Kansas State University Libraries

New Prairie Press

\title{
AN INDIVIDUAL-PLANT GROWTH SIMULATION MODEL FOR QUANTIFYING PLANT COMPETITION
}

William J. Price

Bahman Shafii

Donald C. Thill

Follow this and additional works at: https://newprairiepress.org/agstatconference

Part of the Agriculture Commons, and the Applied Statistics Commons

\section{c) (1) $\Theta$}

This work is licensed under a Creative Commons Attribution-Noncommercial-No Derivative Works 4.0 License.

\section{Recommended Citation}

Price, William J.; Shafii, Bahman; and Thill, Donald C. (1994). "AN INDIVIDUAL-PLANT GROWTH SIMULATION MODEL FOR QUANTIFYING PLANT COMPETITION," Conference on Applied Statistics in Agriculture. https://doi.org/10.4148/2475-7772.1346

This is brought to you for free and open access by the Conferences at New Prairie Press. It has been accepted for inclusion in Conference on Applied Statistics in Agriculture by an authorized administrator of New Prairie Press. For more information, please contact cads@k-state.edu. 


\title{
AN INDIVIDUAL-PLANT GROWTH SIMULATION MODEL FOR QUANTIFYING PLANT COMPETITION
}

\author{
William J. Price and Bahman Shafii, Statistical Programs \\ Donald C. Thill, Division of Plant Sciences \\ College of Agriculture \\ University of Idaho \\ Moscow, ID 83844
}

\begin{abstract}
Plant competition models traditionally have used population or stand level parameters as a basis for modeling. While such models may be valid with regard to average responses, they fail to account for important factors such as within stand variability and spatial relationships. This translates to an assumption of uniformity in growth characteristics among individual plants as well as an equidistant spacing arrangement which are unlikely in real populations. One alternative is to model the growth characteristics of individual plants separately which, when combined as a system, will inherently have population attributes related to competition. Competition models of this type allow for various combinations of growth patterns and spatial arrangements. An individual-plant based simulation model is introduced and the relationships of model parameters with existing concepts in plant competition are discussed. Models are calibrated to wild oat (Avena fatua) and spring barley (Hordeum vulgare) using data from replicated field experiments in Northern Idaho.
\end{abstract}

\section{INTRODUCTION}

Plant competition models in agriculture typically use the stand or field as a modeling unit (Spitters, 1983; Cousens, et al, 1987; Wilkerson, et al, 1990). Parameters of these models, such as available resources, plant densities, and production (i.e. yields, biomass) are estimated on an area basis. This leads to assumptions of homogeneous populations, where uniformly spaced plants are assumed genetically and phenotypically identical. Additionally, it is assumed that environments are homogeneous and resources are spatially constant. Although these conditions are not likely to exist in the real world, this type of model is often interpreted as reflecting the average response to specific conditions. In this context, the stand level models are useful for predictive purposes and have the added benefit of being relatively simple to compute. However, they are limiting as an exploratory tool.

An alternative strategy for modeling plant competition is to reduce the basic modeling unit from the field to the individual plant level (Aikman, et al, 1980; Huston, et al, 1987; Leersnijder, 1992). The individual plant has unique 
characteristics related to its genetic and phenotypic makeup, as well as its spatial location. Furthermore, the simulated field may have spatial variability in terms of resource availability. This simulation framework is remarkably flexible in that virtually any set of conditions could be modeled. Questions relating to population variability, mixed species competition, heterogeneous environments, and various spatial arrangements may then be explored. Individual- plant models have another interesting attribute. Complex population dynamics which need to be explicitly specified in stand-level models can evolve implicitly from large scale individual level models. In fact, the stand-level models can be regarded as the expected long term response of the individual based models. Thus, behavioral characteristics of a given stand-level model under variable agronomic and environmental conditions, may be investigated with the individual-plant model.

Although individual-plant models have many positive characteristics, they also possess certain limitations. Unlike the stand level models, they are not suited for predictive purposes. Detailed information on every plant and the surrounding environment is not practically and easily available for real world applications. The individual-plant model must be viewed in the proper setting as a research tool for hypothesis exploration. Individual-plant models are also computationally intense. Typically, every plant must be modeled separately for each time increment, leading to hundreds or thousands of computations. Efficient use of modeling languages, algorithms, and computing platforms is necessary to make these models practical.

This paper will introduce a simple individual-plant based competition model for wild oat (Avena fatua) and spring barley (Hordeum vulgar) with respect to population density responses in mono and mixed cultures. Empirical calibration and model validation are demonstrated with reference to replicated field experiments in Northern Idaho.

\section{METHODS}

The basis used for the individual-plant model is a circle which has two dimensions. The restriction to a two-dimensional space was determined to be sufficient to simulate biomass accumulation and is analogous to similar concepts commonly used in forestry (Clutter, J. C. et. al., 1983). Further extrapolation to a three-dimensional shape was not considered necessary and would prove costly in terms of computational requirements. Models using the circle as a shape are not prone to changes due to differences in orientation. The circle also has the added attribute that calculations for its characteristics (i.e. area, diameter) are rather simple.

The important characteristics of the plant are its radius and its spatial location determined by the circle center. These attributes are utilized in two governing principles which guide the plant's development. The first principle is the resource (i.e. light, water, nutrients, etc) demand made by the plant. All resources within the area of the circle are potentially available however, the degree of resource requested by a plant is a function of the distance from the resource to the plant's center. This is given by the following exponential expression:

$$
D_{\mathrm{ij}}=\exp \left(-\alpha_{\mathrm{i}}^{*} \mathrm{DIST}\right)
$$


where

$\mathrm{D}_{\mathrm{ij}}=$ proportion of total resource demanded at position $\mathrm{j}$ in plant $\mathrm{i}$, $\alpha_{i}=$ constant related to the rate of resource demand by plant $i$, and DIST $=$ distance from position $\mathrm{j}$ to the plant center $(\mathrm{cm})$.

The above specification assumes diminishing resource demand as distance from the plant center increases (Figure 1). Similar relationships for light flux and depth in multiple plant canopy structures have been described by Charles-Edwards, D.A., et. al. (1986).

The second principle regulates plant growth. In this case, growth is defined as an increase in the circle radius and is determined after all resources available to the plant circle are evaluated. The new radius is determined according to the cumulative logistic function:

$$
\mathrm{R}_{\mathrm{i}(\mathrm{t}+1)}=\mathrm{R}_{\mathrm{MAXi}} /\left(1+\exp \left(\mathrm{k}^{*} \mathrm{U}_{\mathrm{i}(\mathrm{t})}\right)\right)
$$

where

$$
\begin{aligned}
& \mathrm{R}_{\mathrm{i}(\mathrm{t}+1)}=\text { new radius of plant } \mathrm{i}(\mathrm{cm}) \text { at time } \mathrm{t}+1 \\
& \mathrm{R}_{\mathrm{MAX} i}=\text { maximum attainable radius for plant } \mathrm{i} \text { without competition }(\mathrm{cm}), \\
& \mathrm{k}=\text { constant related to growth rate, and } \\
& \mathrm{U}_{\mathrm{i}(\mathrm{t})}=\text { Cumulative proportion resource actually realized for the ith plant at } \\
& \text { time t, i.e. } \\
& \quad \mathrm{U}_{\mathrm{i}(\mathrm{t})}=\mathrm{P}_{\mathrm{i}(\mathrm{t})}+\mathrm{U}_{\mathrm{i}(\mathrm{t}-1)} \text {, where } \\
& \quad \mathrm{P}_{\mathrm{i}} \text { is the proportion of resources acquired by plant } \mathrm{i} \text { at time } \mathrm{t} .
\end{aligned}
$$

This results in time being measured relative to the developmental stage of the plant (Figure 2). An important feature of this model is the relative growth rate parameter, $\mathrm{k}$, which is assumed constant for all plants. Thus, all plants approach their maximum radii at the same rate, but because the maximum radius of each plant may differ, the actual growth rates $(\mathrm{cm} /$ time increment) may vary. This was done as a simplification of the model and was considered feasible since the target plants of the simulation (Wild oat and spring barley) are similar in growth patterns (Morishita, 1988). Variable growth rates among plants may be more applicable for other situations.

In order to assess model output, a relationship between the circular model form and plant biomass was defined as:

$$
\mathrm{B}=\mathrm{C} * \mathrm{R}_{\text {Final }}^{2} / \mathrm{R}_{\text {MAX }}^{2}
$$

where

$$
\begin{aligned}
& \mathrm{B}=\text { Biomass }(\mathrm{g}) \\
& \mathrm{C}=\text { Biomass }(\mathrm{g}) \text { of a single plant grown without competition, } \\
& \mathrm{R}_{\text {Final }}=\text { Circle radius at final time period, and } \\
& \mathrm{R}_{\mathrm{MAX}}=\text { Maximum attainable radius of a given plant. }
\end{aligned}
$$

Equation 3 describes a quantity proportional to the amount of biomass that the plant can be expected to achieve in isolation, $\mathrm{C}$. The proportionality is given by the ratio 
of the final radius and the maximum attainable radius.

\section{Simulation Algorithm}

The area or field in which plants were simulated was divided into an array of $1 \mathrm{~cm}^{2}$ cells. Each cell had predefined initial resource levels which were reset at the beginning of each time increment. Due to the similarity in resource requirements of the species, all resources such as light, water, and nutrients, were considered as one entity (resource space). If more disparate species were included in the simulation, separate modeling of each resource may be required. The growing season was divided into 50 equal length periods and assessment of all plants was done independently and in a random order. Resources are extracted from field cells on a first come-first serve basis. As more plants are assessed, the resource levels of field cells become lower or, if taxed heavily, depleted. Thus, plants assessed later in the time period may find the resources for particular cells diminished by preceding plants, and therefore, may not acquire all the resources they requested. This created a competitive mechanism within the model. Plants which received insufficient resources grew less than plants which had all resource demands met (Figure 3). If plants received no resources, then growth for that time period was zero. Plants were not allowed negative growth, and density dependent mortality was not considered. This assessment process was repeated until all time periods were completed (Figure 4). Relevant plant characteristics (i.e. position, radius, and $R_{M A X}$ ) were then recorded.

All simulations were written in the $\mathrm{C}$ language and compiled under Borland $\mathrm{C}++$ compiler 4.0 (Borland, 1993). Simulation runs were conducted on an Intel 486DX2-66 platform under MicroSoft Windows 3.1. Several adjustments were made during the course of the simulations to increase the simulation speed and decrease the required memory. The final program could accommodate up to 4000 plants with an average execution time of 10 minutes per run. The total number of plants simulated for the work described below encompassed more than 1.3 million plants. Statistical computations and graphics were carried out using SAS/STAT and SAS/GRAPH (SAS, 1991).

\section{Simulations}

\section{EMPIRICAL RESULTS}

Initial monoculture density trials were simulated to observe the sensitivity of density-biomass relationships to model parameter $\left(\mathrm{R}_{\mathrm{MAXi}}\right.$ and $\alpha_{\mathrm{i}}$ ) changes. Plants were placed in $9-\mathrm{cm}$ rows and the density within rows was manipulated to obtain a range of 10 plants $\mathrm{m}^{-2}$ to 600 plants $\mathrm{m}^{-2}$. This range represented what might be found in actual field conditions for a cereal crop. Model parameters were systematically varied from 0.005 to 1.0 for $\alpha_{i}$, and from 10 to $100 \mathrm{~cm}$ for $\mathrm{R}_{\mathrm{MAX}}$, respectively.

Under this scenario, some interesting observations were made. For all $\alpha$ and $\mathrm{R}_{\mathrm{MAX}}$ combinations, biomass per plant asymptotically decreased as plant density increased. Likewise, biomass per area $\left(\mathrm{g} \mathrm{m}^{-2}\right)$ asymptotically increased with 
increasing plant density (Figure 5). Such behavior accurately reflects real phenomena (Cousens, et. al., 1987; Spitters, 1983) and results from limited resources among the plants. With finite resource availability, the amount allocated to each plant decreases as density increases. Biomass $\left(\mathrm{gm}^{-2}\right)$ still increases, however, because the rate of population increase is faster than the rate of decrease for biomass per plant. Eventually biomass per plant approaches zero and biomass $\left(\mathrm{gm}^{-2}\right)$ becomes constant. However, this point is not reached for real data due to density dependent mortality which limits population increases.

A common model for describing the density-biomass relationship is given by the hyperbolic function:

$$
\mathrm{B}=\mathrm{a} /(1+\beta \mathrm{N})
$$

where

$$
\begin{aligned}
& B=\text { biomass per plant }\left(g \text { plant }{ }^{-1}\right) \\
& a=\text { biomass of a plant grown without competition }(g), \\
& \beta=\text { coefficient of intraspecific competition, and } \\
& \left.N=\text { plant density (plant } m^{-2}\right)
\end{aligned}
$$

This model was found to fit the simulated biomass results very well for all $\alpha$ and $\mathrm{R}_{\mathrm{MAX}}$ combinations, and hence was used to assess sensitivity to changes in simulation parameters. For example, the range of $\alpha$ was determined to be restricted to .01 to .10 , since values outside of this range gave little or no change in the estimated least squares fit of (4). $\mathrm{R}_{\operatorname{MAX}}$ was restricted to be positive. Although changes in both $\alpha$ and $\mathrm{R}_{\mathrm{MAX}}$ affected the estimates, $\mathrm{R}_{\operatorname{MAX}}$ showed the most influence on estimates of $\beta$. Since $\beta$ is considered to be a measure of aggresivity (Spitters, 1983) hence, by analogy, the combination of $\alpha$ and $\mathrm{R}_{\operatorname{MAX}}$ may also be an indication of relative aggresivity. Examination of the association between $\beta$, $\alpha$, and $\mathrm{R}_{\mathrm{MAX}}$ revealed a strong linear relationship between $\beta$ and $\alpha$ and $\mathrm{R}_{\mathrm{MAX}}$ combinations (data not shown). In general, larger $\mathrm{R}_{\mathrm{MAX}}$ values and smaller $\alpha$ values lead to larger $\beta$ values, and thus, higher levels of aggresivity.

$\mathrm{R}_{\mathrm{MAX}}$ and $\alpha$ also show a proportional relationship to biomass production. As might be expected from (3), increases in radius will result in increased biomass (Figure 6a). In addition, large values of $\alpha$ in (1) result in a resource use curve with a steeper slope (i.e. lower resource demand) than that of smaller values. Therefore, under similar conditions, higher $\alpha$ values will result in more growth (less resource demand implies less competition) and more biomass production (Figure 6b).

\section{Calibration and Validation}

The data used for the purpose of model calibration and validation were collected at the University of Idaho experimental farm, Moscow, Idaho during 1987 and 1988 (Tapia, 1990). Five densities of spring barley and wild oat were used each year in an addition-series design. The plants were in $9-\mathrm{cm}$ rows with the species set perpendicular to each other. Above ground biomass was recorded biweekly for five 
periods. Data for 1987 and 1988 were combined and a supplemental data set from 1993 was also added to provide an adequate range of actual plant densities for calibration of each species. The 1993 data arose from 20 plants of each species grown individually without competition. Biomass for these plants was recorded at the end of the growing season.

A schematic representation of the addition series data is given in Figure 7. The data set is broken into monoculture spring barley, monoculture wild oat, and mixed species. The calibration process utilized the final monoculture biomass data of each species and the 1993 individual plant data.

Simulated densities of each species were chosen to match the observed monoculture densities and the plants were arranged to reproduce the $9-\mathrm{cm}$ row spacing. The simulated field consisted of four replications of $1.5 \mathrm{~m}^{2}$ from which the middle $1 \mathrm{~m}^{2}$ was measured. This was done to avoid border effects which were evident in the initial simulations. Several sets of the replicated simulations were then run which differed only by incremental changes in the plant parameters $\mathrm{R}_{\mathrm{MAX}}, \alpha$, and C. All plants within a species had the same parameter settings which were chosen to cover expected biological ranges. At the final time period, biomass was determined for each plant within the middle $1 \mathrm{~m}^{2}$.

\section{Calibration Assessment}

The ordinary least squares fit to (4) was used as the basis for two calibration assessment statistics. The first is a residual sum of squares defined as:

$$
\mathrm{SS}_{\mathrm{RES}}=\Sigma\left(\mathrm{Y}_{\mathrm{i}}-\hat{\mathrm{Y}}_{\mathrm{i}}\right)^{2}
$$

where

$$
\begin{aligned}
& \mathrm{Y}_{\mathrm{i}}=\text { observed plant biomass values, and } \\
& \hat{\mathrm{Y}}_{\mathrm{i}}=\text { predicted values generated from fitted simulation to the } \\
& \text { hyperbolic model. }
\end{aligned}
$$

Defining the residuals in this manner was necessary because the simulated and observed densities rarely coincided exactly. In this case, predicted values generated from the fitted simulated data were considered highly correlated with observed values ( $r>.98)$ and therefore a good proxy for the simulated data. The $\mathrm{SS}_{\mathrm{RES}}$ was minimized over the expected parameter ranges to determine the best fit to the observed data.

An alternative measure was also examined which compared least squares fits of the hyperbolic model, (4), to actual and simulated data. This was given by:

$$
\operatorname{AREA}=\left|\int f\left(N_{i}\right)-\int g\left(N_{i}\right)\right|
$$

where

$\mathrm{f}\left(\mathrm{N}_{\mathrm{i}}\right)=$ hyperbolic model fitted to observed data, and $\mathrm{g}\left(\mathrm{N}_{\mathrm{i}}\right)=$ hyperbolic model fitted to simulated data. 
The above expression representing the 'area' between the two curves was also minimized to locate the appropriate plant parameters.

Both measures converged on one set of parameter values for each species (Table 1). The estimates for single plant biomass, $C$, and maximum radius, $\mathbf{R}_{\mathrm{MAX}}$, are relatively similar for both species. The estimated resource demand parameter, $\alpha$, however, is quite different between the two species $(0.06$ and 0.02 for spring barley and wild oat, respectively). This would suggest that wild oat is relatively more aggressive (has a higher resource demand) than spring barley. Aggressivity, however, must be interpreted as a balance of both $\alpha$ and $\mathrm{R}_{\mathrm{MAX}}$. Since no appropriate measures of error for the parameter estimates were available, the significance of difference in aggressivity of the two species could not be tested.

The fitted hyperbolic models based on data generated from these parameter values showed little difference from their least squares counterparts fitted to the real data. In fact the two lines are all but indistinguishable (Figure 8). For both species, the resulting models followed the data well and the corresponding residual plots indicated no trends or detectable patterns (data not shown).

\section{Validation Assessment}

Validation assessment was carried out in a similar manner to calibration using the remaining mixed species addition series data (Figure 7), and the dual species hyperbolic model (Spitters, 1983):

$$
\mathrm{Y}_{\mathrm{ii}}=\mathrm{a} /\left(1+\beta_{1} \mathrm{~N}_{\mathrm{i}}+\beta_{2} \mathrm{~N}_{\mathrm{i}^{\prime}}\right)
$$

where

$\mathrm{Y}_{\mathrm{ii}^{\prime}}=$ biomass of species $\mathrm{i}$ grown in competition with species $\mathrm{i}^{\prime}$,

$\mathrm{a}=$ biomass of species $\mathrm{i}$ grown without competition,

$\beta_{1}=$ intraspecific competition coefficient,

$\beta_{2}=$ interspecific competition coefficient.

$\mathrm{N}_{\mathrm{i}}=$ density of species $\mathrm{i}$, and

$\mathrm{N}_{\mathrm{i}^{\prime}}=$ density of species $\mathrm{i}^{\prime}$.

Parameter estimates for both species under observed and simulated data are given in Table 2. Estimated parameter values generated from simulated spring barley biomass are reasonably close to the corresponding observed data estimates, with the widest difference indicated in the interspecific coefficient for wild oat. In the case of wild oat biomass, the interspecific coefficient for spring barley is the only consistent estimate. Thus, in both cases, the wild oat related parameters show the most discrepancy.

Validation residuals are defined as $\left(Y_{i}-\hat{Y}_{i i}\right)$ where $Y_{i}$ is the observed data value and $\hat{\mathrm{Y}}_{\mathrm{ii}}$ is the predicted value from (7). Residual plots for both species are given in Figure 9. These indicate that barley biomass was modeled better than wild oat biomass. This difference could be due to a lack of resolution in calibrating the wild oat model. Wild oat showed a larger variability in plant biomass than did spring 
barley and thus, it could not be as precisely modeled. The calibration assessment techniques were also dependent on the least squares fit of the hyperbolic model to the observed data which might have been influenced by variable data. Data augmentation for wild oat could improve calibration accuracy. Specifically, since most of the biomass variability occurs at low densities, additional data in this range would help improve the least squares fit and, thus, the overall calibration process.

\section{CONCLUDING REMARKS}

The parameters of the model presented are associated with the plant's aggressivity and are closely related to traditional coefficients of competition. Calibration of the model to monoculture data for spring barley and wild oat provided a precise representation of the monoculture system of each species with respect to density relationships. Some improvements in the accuracy of mixed culture simulations are needed, however, which may be achieved through provision of additional data for the calibration process. Application of different functional forms for plant growth and resource demand relationships may also be necessary to achieve better representations of both species. This is particularly true of the resource demand function where direct empirical information is scarce.

Individual-plant based models could provide more flexibility than stand level counterparts for exploring the influence of heterogeneous populations, environments, and spatial arrangements on plant competition. They would allow for a broad exploration of plant competition issues, the results of which, may be incorporated into more traditional stand level prediction models.

\section{ACKNOWLEDGEMENTS}

Contribution from the College of Agriculture, University of Idaho, Idaho Agricultural Experiment Station paper number 9401.

\section{REFERENCES}

Aikman, D. P. and A. R. Watkinson. 1980. A model for growth and self thinning in even aged monocultures of plants. Ann. Bot. 45: 419-427.

Borland International Inc. 1993. Borland $\mathrm{C}++$ Compiler version 4.0, Borland International Inc., Scotts Valley, CA.

Charles-Edwards, D. A., D. Doley, and G. M. Rimmington. 1986. Modelling plant growth and development. Academic Press. Sydney, AU.

Clutter, J. L., J. C. Fortson, L. V. Pienaar, G. H. Brister, and R. L. Bailey. 1983. Timber management a quantitative approach. John Wiley and Sons, NY. 
Cousens R., S. R. Moss, G. W. Cussans, and B. J. Wilson. 1987. Modeling weed populations in cereals. Rev. Weed Sci. Weed Sci. Soc. Am. 3: 93-112.

Huston, M. D., D. DeAngelis, and W. Post. 1988. New computer models unify ecological theory. Bioscience. 38: 682-691.

Leersnijder, R. P. 1992. PINOGRAM: A pine growth area model. Eco. Mod. 61: $1-147$.

Morishita, D. W. and D. C. Thill. 1988. Wild Oat (Avena fatua) and Spring Barley (Hordeum vulgare) growth and development in monoculture and mixed culture. Weed Science, 36: 43-48.

SAS Institute Inc. 1991. SAS/GRAPH User's Guide, Version 6, First Edition, Vol 1-2. SAS Institute Inc, Cary, NC.

SAS Institute Inc. 1991. SAS/STAT User's Guide, Version 6, Fourth Edition, Vol 2. SAS Institute Inc, Cary, NC.

Spitters, C. J. T., 1983. An alternative approach to the analysis of mixed cropping experiments. 1. Estimation of comeptition effects. Neth. J. Ag. Sci. 31: 111.

Tapia, L. S. 1990. Intraspecific and interspecific competition effects on spring barley (Hoedeum vulgare) and wild oat (Avena fatua) growth and development. $\mathrm{Ph} \mathrm{D}$. Dissertation. University of Idaho.

Wilkerson, G. G., J. W. Jones, H. D. Coble, and J. L. Gunsolos. 1990. SOYWEED: A simulation model of soybean and common cocklebur growth and competition. Agron. J. 82: 1003-1010. 
TABLE 1. Results of monoculture calibration of wild oat and spring barley.

\begin{tabular}{|c|c|c|}
\hline & Spring & Wild \\
\hline Parameter & Barley & Oat \\
\hline $\mathrm{C}$ & $38 \mathrm{~g}$ & $40 \mathrm{~g}$ \\
\hline $\mathrm{R}_{\text {MAX }}$ & $30 \mathrm{~cm}$ & $28 \mathrm{~cm}$ \\
\hline$\alpha$ & 0.06 & 0.02 \\
\hline
\end{tabular}

TABLE 2. Estimated parameter values for the dual species hyperbolic model fitted to observed and simulated biomass values for spring barley and wild oat.

\begin{tabular}{lll}
\hline Observed & Spring Barley & Simulated \\
\hline $\mathrm{A}=0.0127$ & & $\mathrm{~A}=0.0214$ \\
$\beta_{1}=0.0006$ & $\beta_{1}=0.0005$ \\
$\beta_{2}=0.0003$ & & \\
& & \\
Observed & Wild Oat & Simulated \\
\hline $\mathrm{A}=0.0251$ & & $\mathrm{~A}=0.0478$ \\
$\beta_{1}=0.0017$ & $\beta_{1}=0.0005$ \\
$\beta_{2}=0.0006$ & $\beta_{2}=0.0004$ \\
\hline
\end{tabular}




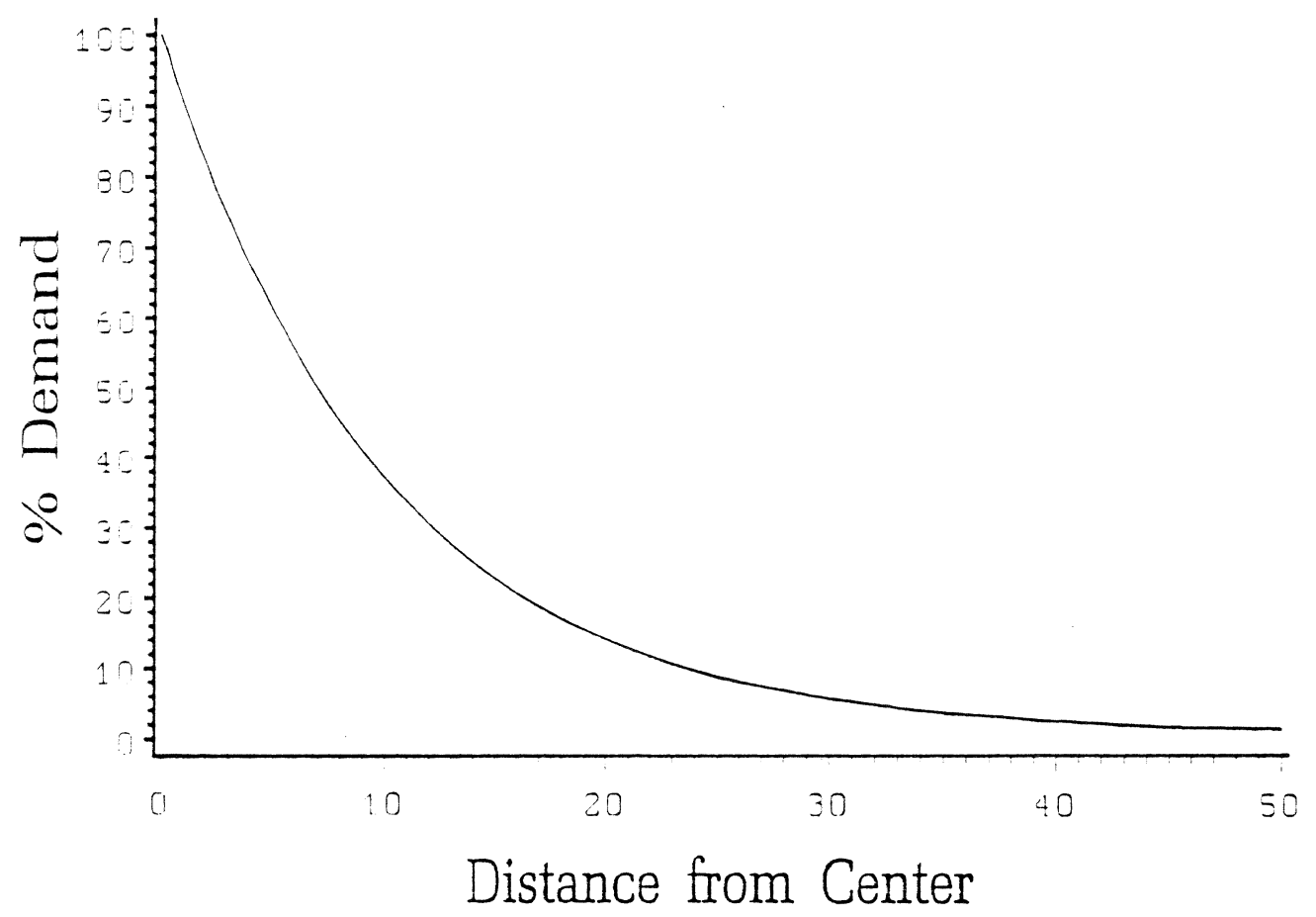

Figure 1 Resource demand as a function of distance from the plant center.

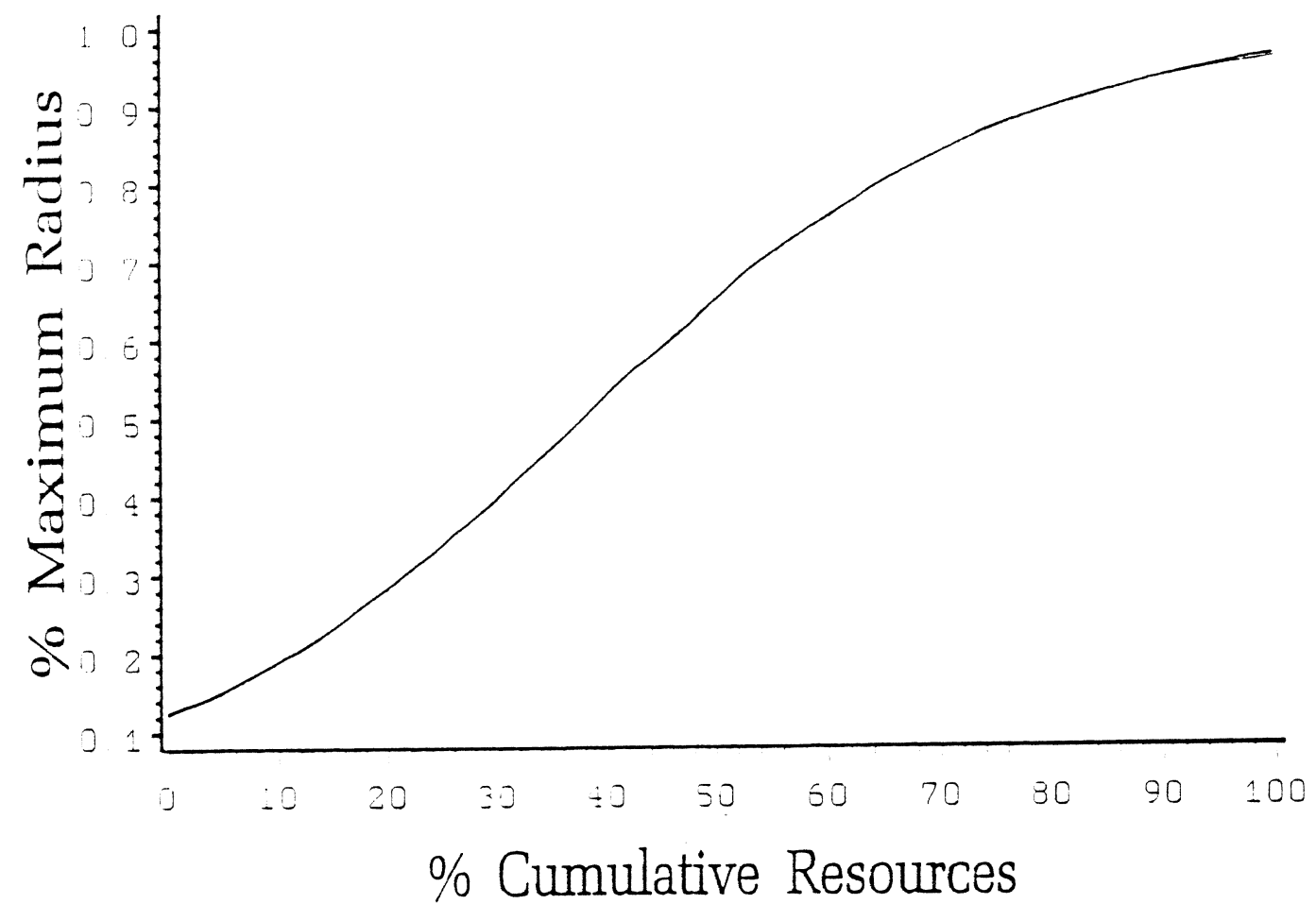

Figure 2 Cumulative logistic growth describing increase in plant radius as a function of total resources used. 


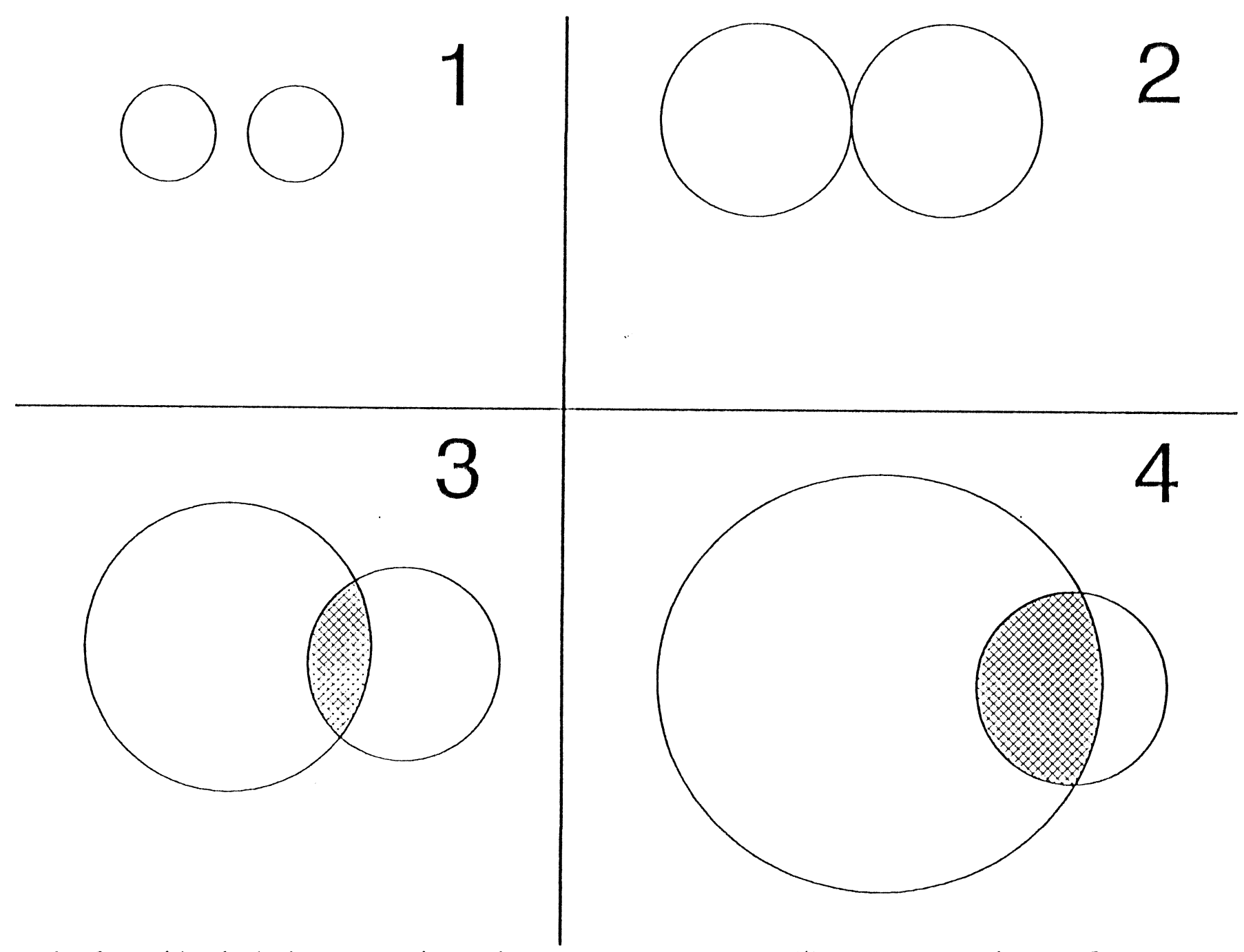

Figure 3 Growth of two identical plants over time: plants start at same stage (1), grow at equal rates (2), overlapping occurs (3), one plant becomes dominant (4). 


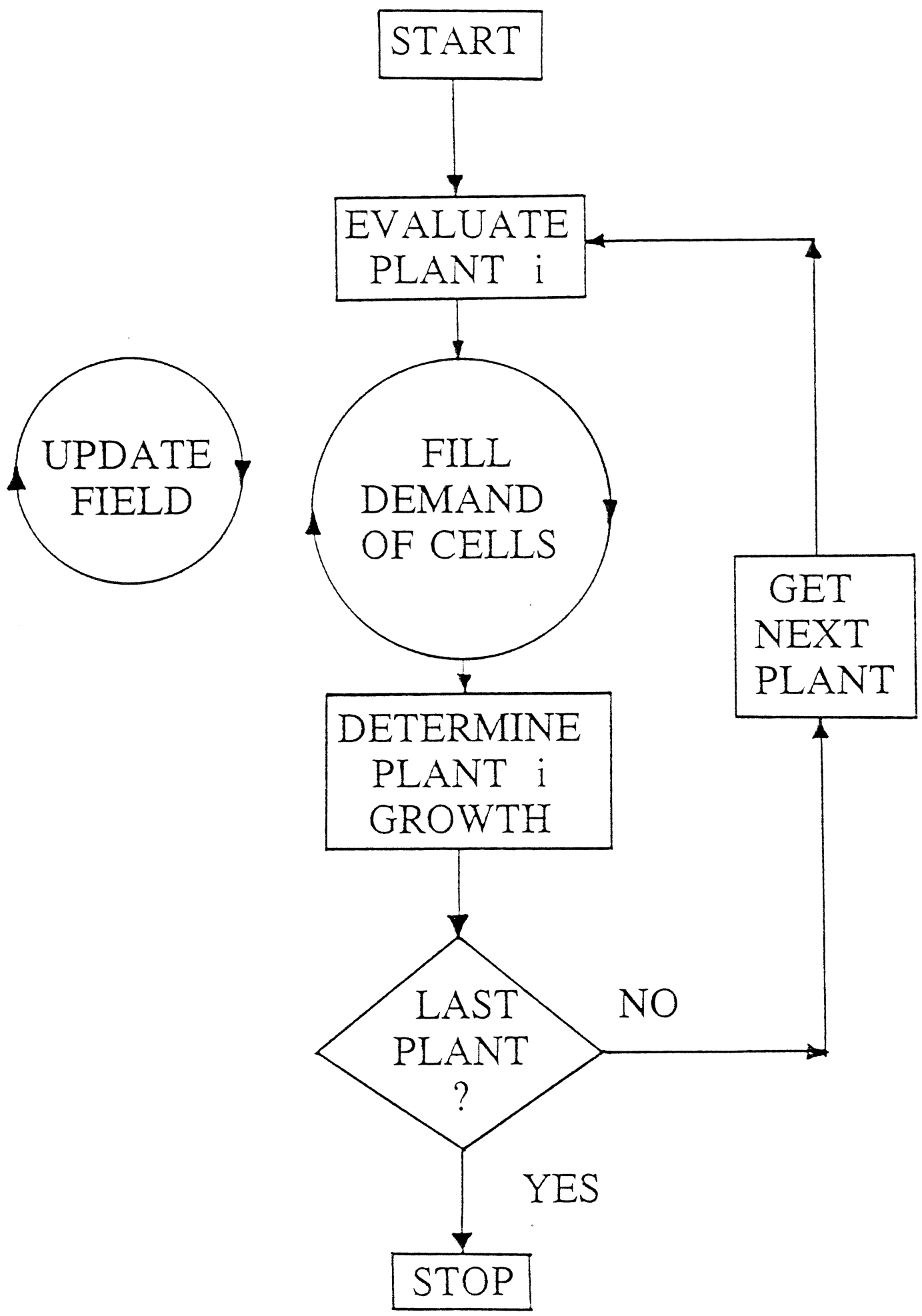

Figure 4 Flow chart for the simulation algorithm. 


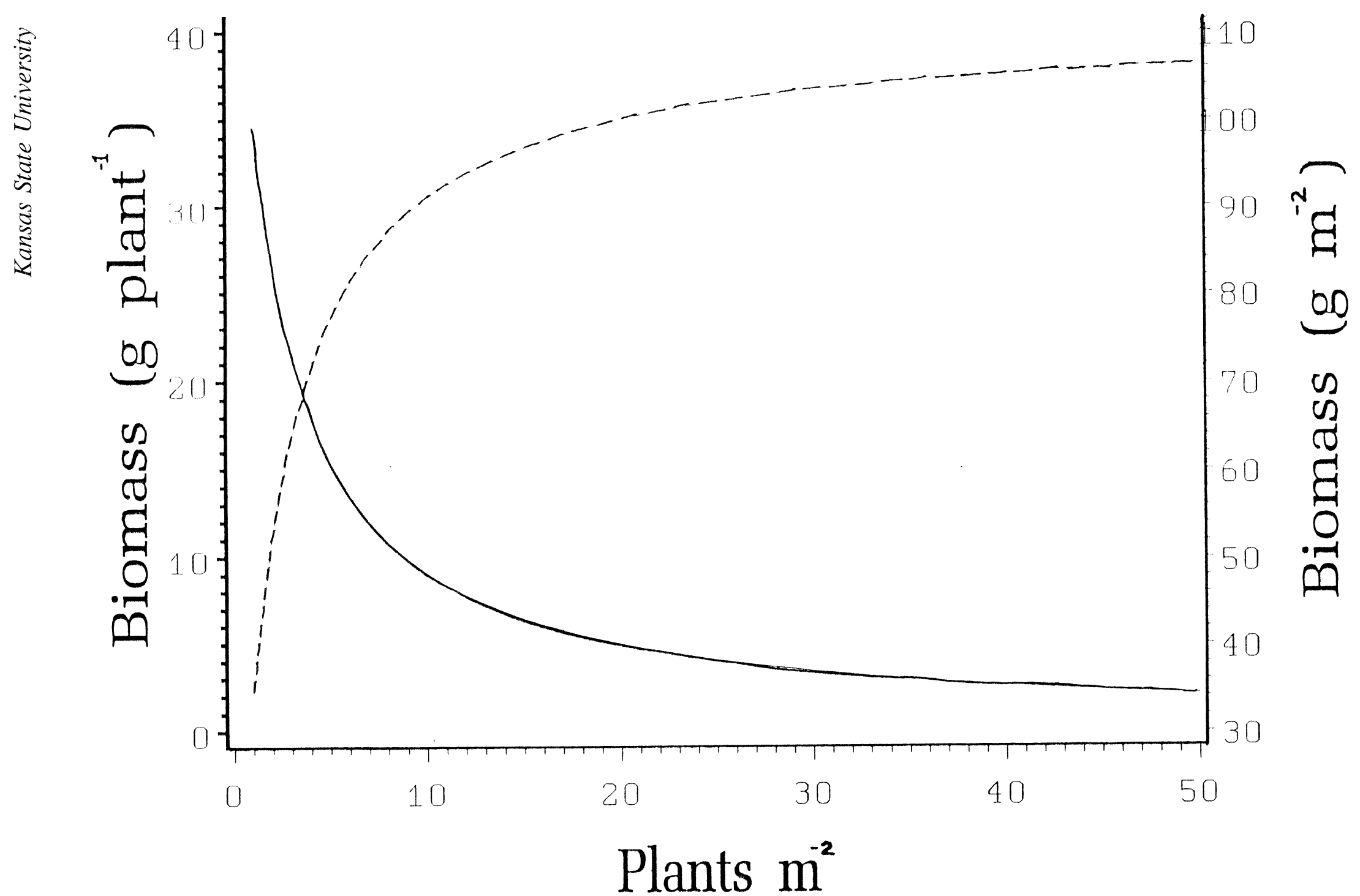

Figure 5 Simulated changes in plant biomass measures with increasing plant density. Solid line indicates biomass per plant $\left(\mathrm{g}\right.$ plant $\left.{ }^{-1}\right)$ and dashed line indicates biomass per unit area $\left(\mathrm{g} \mathrm{m}^{-2}\right)$. 


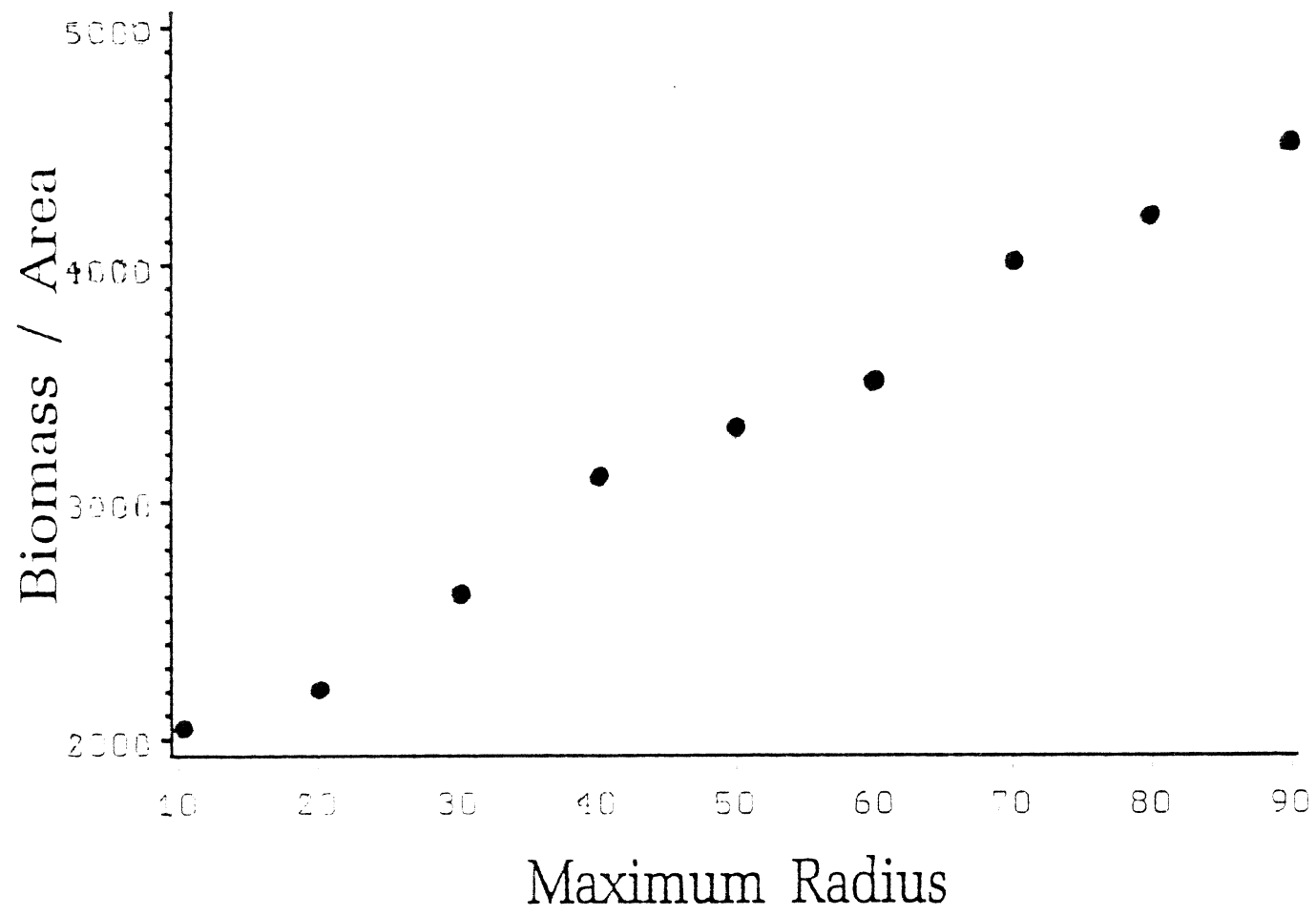

Figure 6a Proportional increase in biomass $\mathrm{m}^{-2}$ with increasing values of the maximum radius n

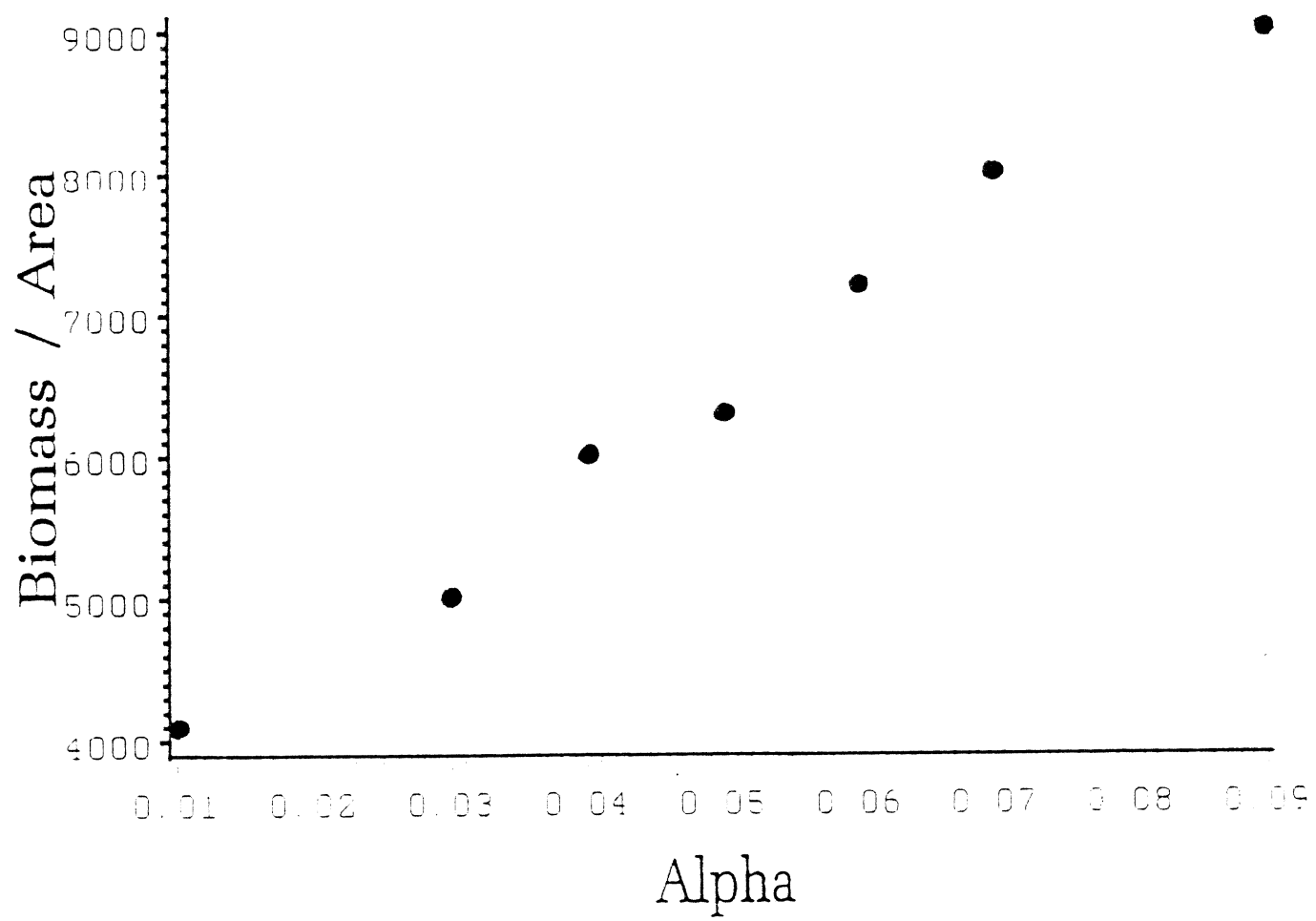

Figure $6 \mathrm{~b}$ Proportional increase in biomass $\mathrm{m}^{-2}$ with increasing values of the resource demand parameter $\alpha$. 


\section{Planned S. Barley and W. Oat Densities}

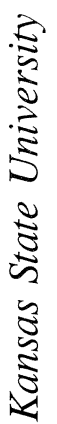

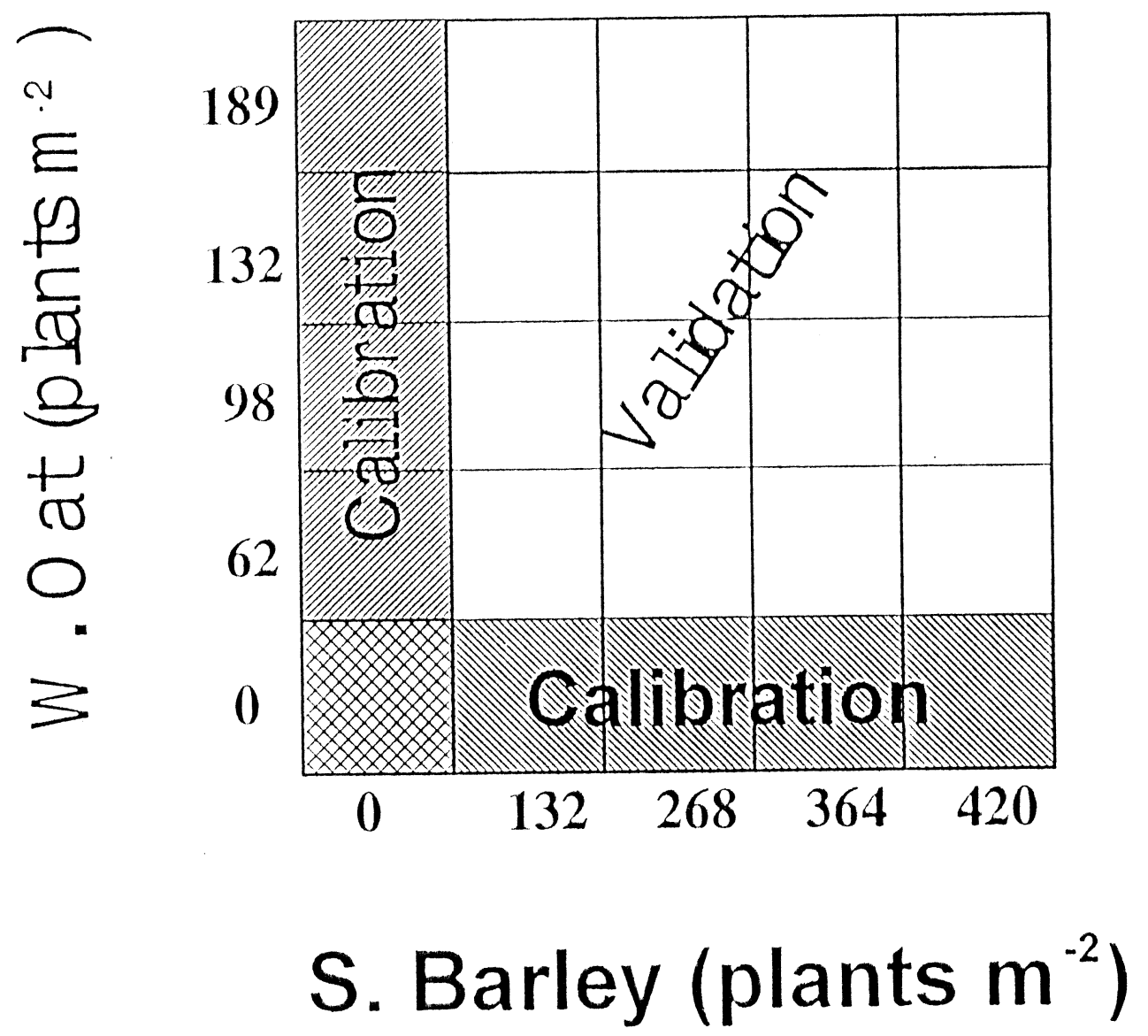

$\because \quad$ Figure 7 Schematic representation of the planned spring barley and wild oat densities used in the addition series design. 


\section{Spring Barley}

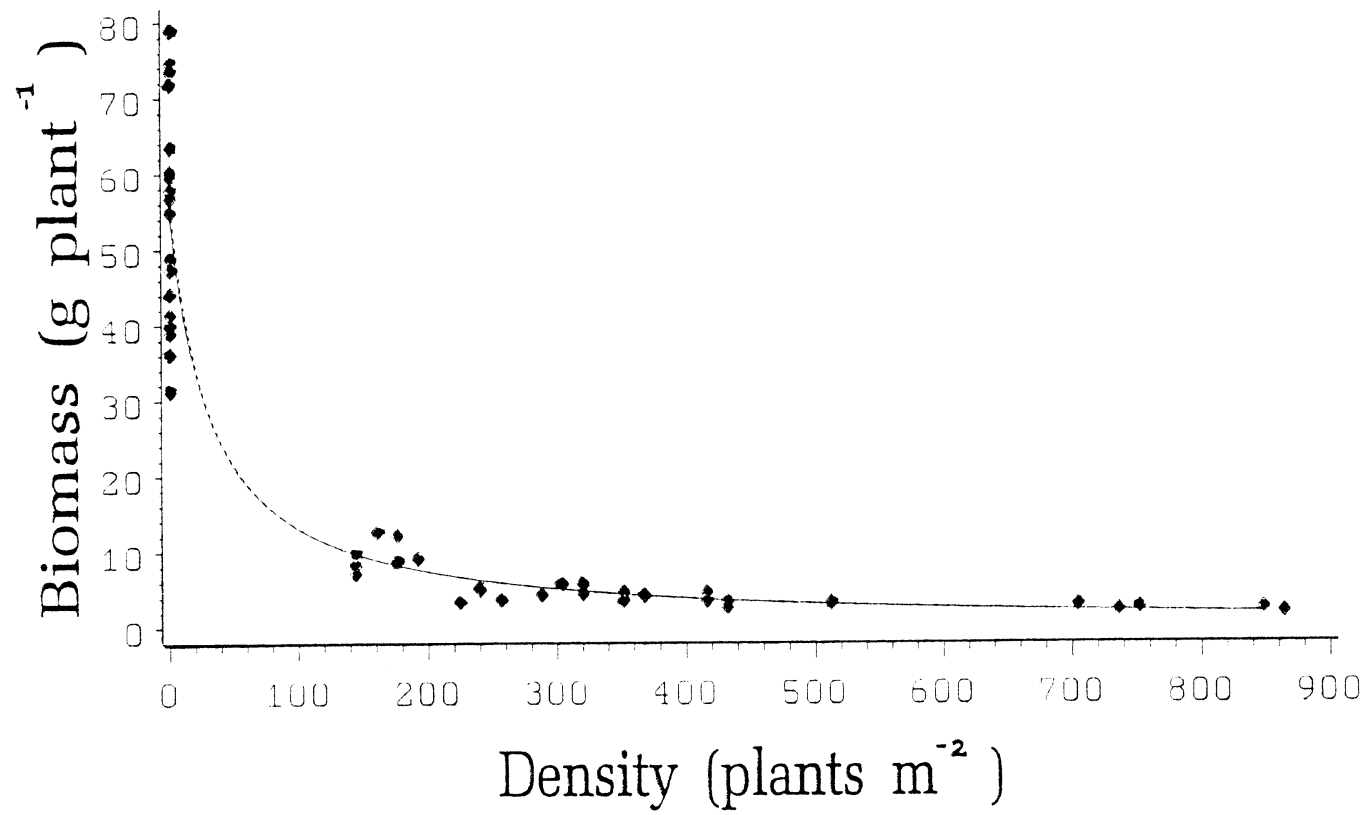

Wild Oat

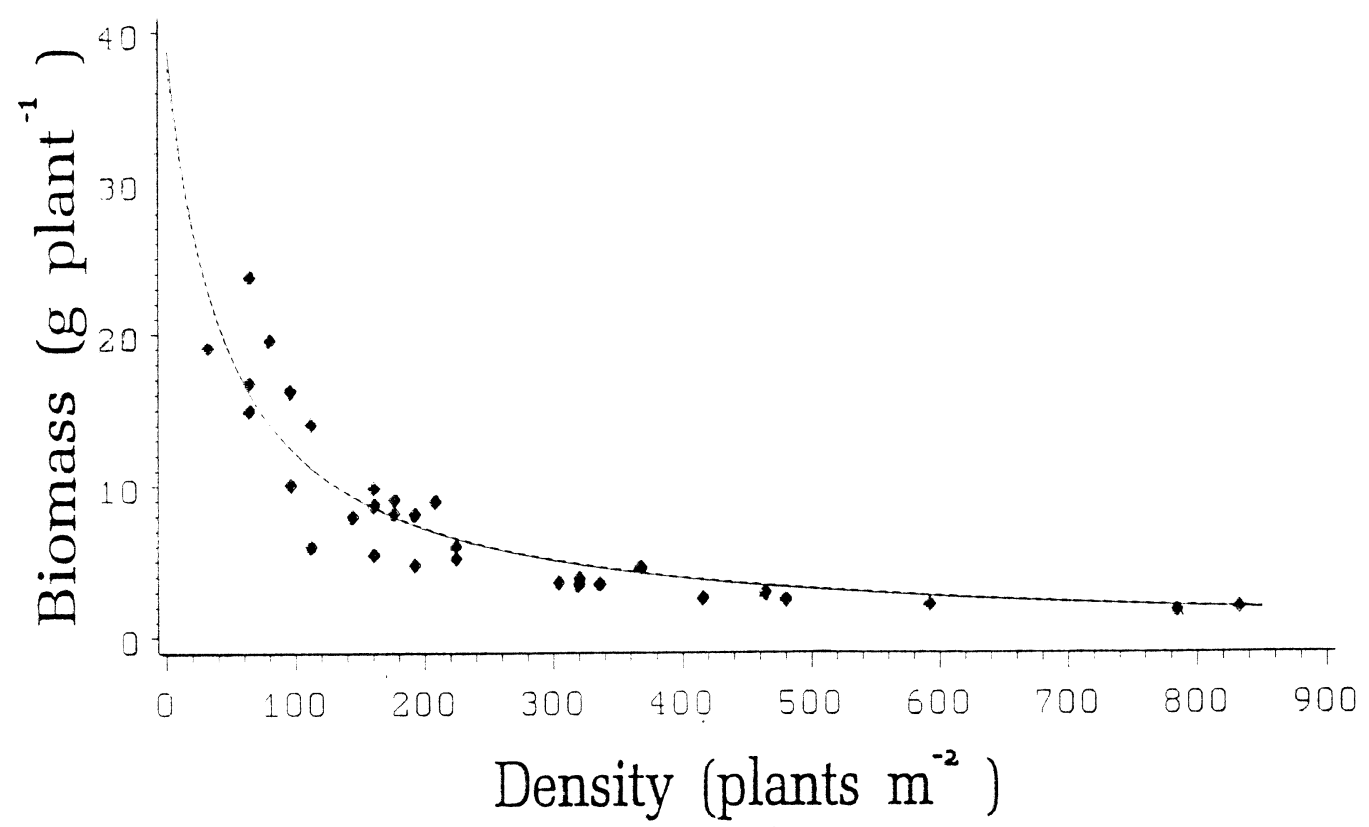

Figure 8 Model calibration results for spring barley and wild oat. Curves represent the hyperbolic function fits to the observed data (dashed line) and the model generated data (solid line). Notei the lines are nearly coincidental. 


\section{Spring Barley (a)}
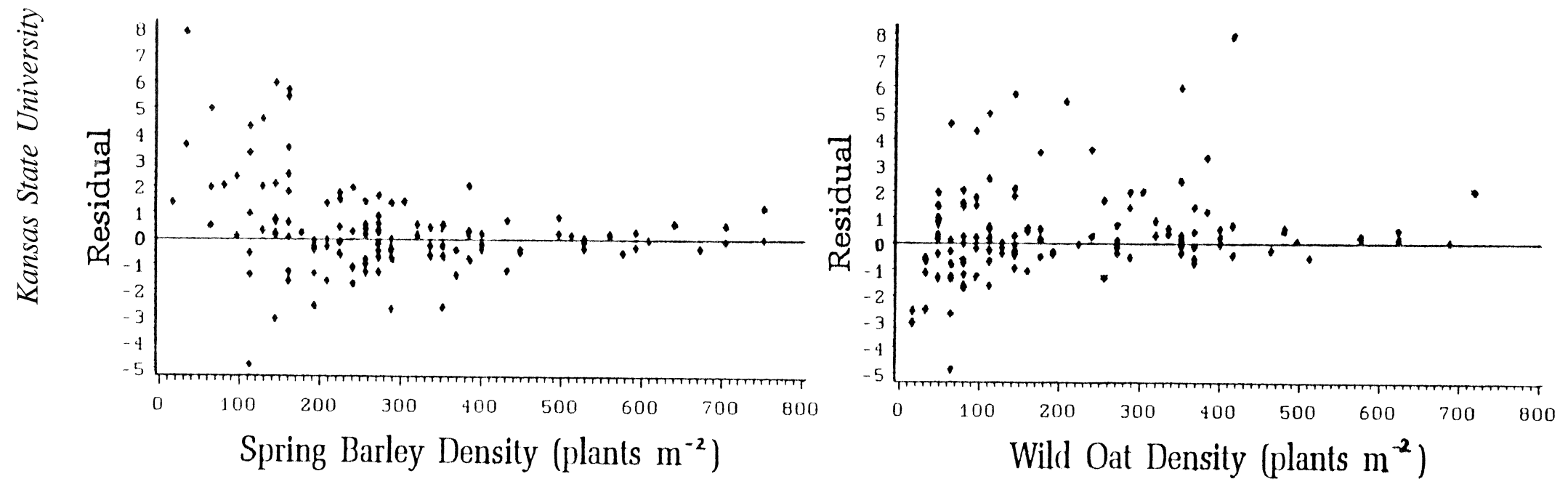

\section{Wild Oat (b)}
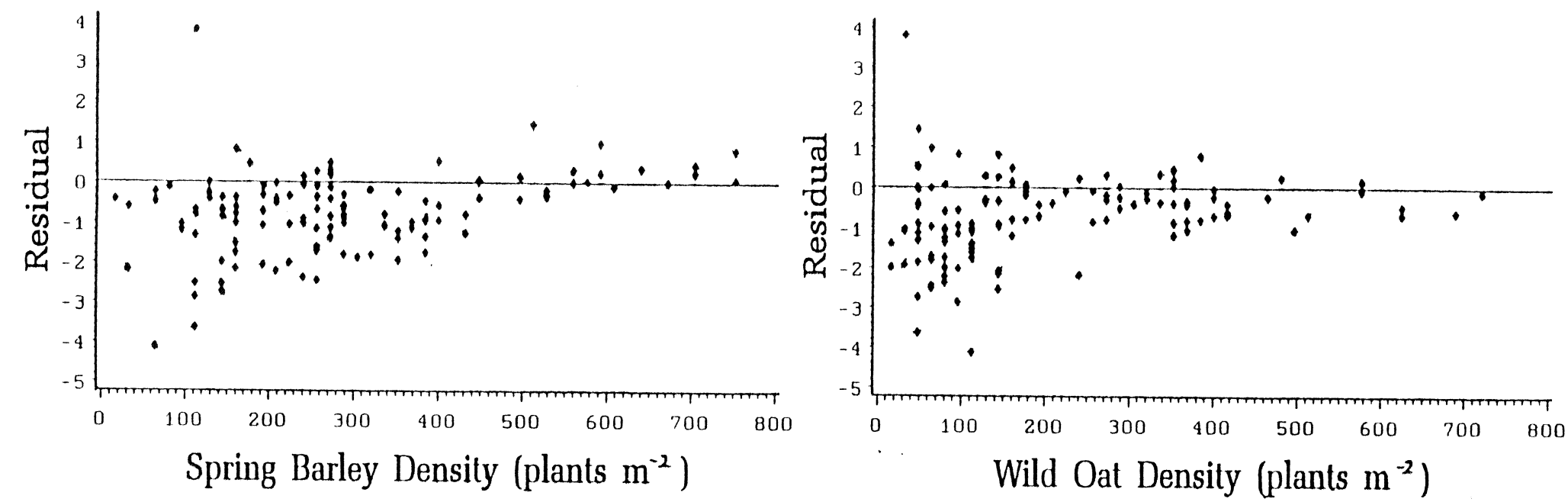

$\stackrel{\infty}{\sim}$ Figure 9 Residual plots for the validation of the spring barley biomass model (a) and wild oat biomass model (b). 